\title{
Author's Reply: a Last Resort When There is No Blood: Experiences and Perceptions of Intraoperative Autotransfusion Among Medical Doctors Deployed to Resource-Limited Settings
}

\author{
Annie Sjöholm ${ }^{1} \cdot$ Andreas Älgå $^{1} \cdot$ Johan von Schreeb $^{1}$
}

Accepted: 7 November 2020/Published online: 29 November 2020

(C) Société Internationale de Chirurgie 2020

We read with interest the constructive comments made by Dr. Raykar et al. [1] on our article "A Last Resort When There is No Blood: Experiences and Perceptions of Intraoperative Autotransfusion Among Medical Doctors Deployed to Resource-Limited Settings" [2]. We agree that walking blood banks are useful but underused and that Hemafuse may be a promising new tool, albeit too expensive. Interestingly, one of the study participants brought up Hemafuse as an alternative to self-built intraoperative autotransfusion. The participant believed that Hemafuse was a simple product with potential utility in resource-limited settings. However, the participant had concerns with the cost-effectiveness of the device and saw the cost as a bottleneck for implementation in these settings.

"I think it would cost 100 dollars per use and it is quite a lot of money for a low-income country... where health budgets per individual may be as much as 20 dollars." (study participant 4 )

The study participants discussed the acceptable level of cost for a simple intraoperative autotransfusion device and believed that a realistic price per use would be 10-20 dollars, when being compared to the cost of one blood unit in resource-limited settings.

"For this single use, I would probably look for something in the range of 10 dollars, if it is re-utilizable... if I am able to use it 10 times... even 100 dollars would be very cheap. Then I would compare

\begin{abstract}
these costs of this device with the cost of a blood
\end{abstract} unit." (study participant 5)

In this perspective, Hemafuse and similar products must be made available at a lower cost for wider implementation to be realistic. Walking blood banks may be a more feasible alternative, but would also require careful planning to allow for systematic implementation. We conclude that further investments are needed to make blood transfusions more widely available. In addition, more operational research is warranted to ensure that optimal models are implemented where blood transfusions are most needed, which continue to be in rural areas of low-income settings.

\section{References}

1. Raykar NP, Jayaram A, Puyana JC, Roy N (2020) Letter to the editor: a last resort when there is no blood: experiences and perceptions of intraoperative autotransfusion among medical doctors deployed to resource-limited settings. World J Surg. https://doi.org/10.1007/s00268-020-05878-4

2. Sjöholm A, Älgå A, von Schreeb J (2020) A last resort when there is no blood: experiences and perceptions of intraoperative autotransfusion among medical doctors deployed to resourcelimited settings. World J Surg 44:4052-4059. https://doi.org/10. 1007/s00268-020-05749-y

Publisher's Note Springer Nature remains neutral with regard to jurisdictional claims in published maps and institutional affiliations.
Annie Sjöholm

annie.sjoeholm@gmail.com

1 Karolinska Institutet, Stockholm, Sweden 